\title{
Stylistic conventions
}

This book uses the Gregorian calendar (with the new year starting on 1 January), rather than the Julian, except in a few instances where clarification requires the use of both possible or relevant years (i.e. 1611/12). Printed material has been quoted verbatim, and I have attempted to retain the original capitalisation, spelling, and punctuation of all archival material. Some normalisations have been adopted for readability, such as the silent extension of contractions or the interchangeable use of letters $i$ and $\mathrm{j}, \mathrm{u}$ and $\mathrm{v}$, and $\mathrm{y}, \mathrm{c}$ and $\mathrm{t}$. Where interchangeable letters do not seem to obstruct the legibility of the word, they have been left in their original form.

Clarification between the financial currencies of $f$ Scots and $f$ Sterling occurs throughout this book, but where not specifically stated it should be assumed that monetary amounts dating to Anna's time in Scotland (15891603) refer to $f$ Scots, whereas those post- 1603 are $f$ Sterling. Discussion of James's decision to rename Anna's principal English residence from Somerset House to Denmark House in 1617 is given in Chapter 2. After this section, to avoid confusion, the palace is referred to as Denmark House irrespective of date except when determined by direct quotes.

Distinction between the kingdoms of England and Scotland are consistently made, although the terms Britain, Great Britain, and British are used on occasion. Such terms are, of course, anachronistic in predating the Acts of Unions of 1707. However, James VI's succession to the English throne engineered a dynastic and personal union of the kingdoms with the formation of a composite Stuart monarchy, and James himself repeatedly used such terms. Furthermore, as Steve Murdoch has demonstrated, Stuart subjects held and asserted a range of local, regional, national, and supra-national identities - including British and Briton - which were not fixed and mutually exclusive but largely dependent on circumstance. ${ }^{1}$

${ }^{1}$ For example, Network North: Scottish Kin, Commercial and Covert Associations in Northern Europe, 1603-1746 (Leiden and Boston, 2006), 49-83; 'James VI and the Formation of a Scottish-British Military Identity', in S. Murdoch and A. MacKillop (eds), in Fighting for Identity: Scottish Military Experience c.1550-1900 (Leiden, 2002), 3-31. 